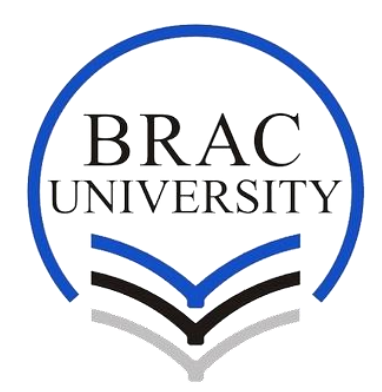

\title{
I-bin: The Intelligent and Entertaining Bin
}

\author{
Thesis Project
}

A Thesis submitted to the Dept. of Electrical \& Electronic

Engineering, BRAC University in partial fulfillment of the requirements for the Bachelor of Science degree in Electrical \& Electronic Engineering

Project Supervisor: Dr. Md Khalilur Rhaman

\author{
Project Group \\ Nolok Noor - 10121080 \\ Mohammad Wasiul Haq - 10121076
}




\section{DECLARATION}

We hereby declare that the thesis titled "I-bin: The Intelligent and Entertaining Bin" is submitted to the Department of Electrical and Electronics Engineering of BRAC University in partial fulfillment of the Bachelor of Science in Electrical and Electronics Engineering. This is our original work and was not submitted elsewhere for the award of any other degree or any other publication.

Date:

Supervisor:

Dr. Md Khalilur Rhaman

Nolok Noor

Student ID: 10121080

Mohammad Wasiul Haq

Student ID: 10121076 


\section{ACKNOWLEDGEMENTS}

Human life will be easier and more comfortable by using any machine with their voice command. The help of modern technology and researches on artificial intelligent, this project came true relatively. This project is a simple implementation of this approach, a robot which is controlled by voice command.

We would like to thanks our supervisor, Dr. Md Khalilur Rhaman, Associate Professor, BRAC University. We could not complete this project without his constant encouragements, valuable insight, motivations and guideline. We also like to thanks our Co-adviser Md. Risul Karim, Lecturer-I, BRAC University. Even though we could not put everyone's name, we would specially like to thank our fellow friend A.M. Reasad Azim Bappy. Additionally we would like to thank our parents and friends for support and encouraging us. 


\begin{abstract}
The object of this project is to develop a program on android device to control a robot to collect discarded material using human voice and can detect hindrance. In this recent time, android device as a user and as developer is become more popular. So we have selected android based device which have Google voice command and developed an application to control the robot to get a desirable output. We can communicate with the robot from the android device by a Bluetooth module which is connected to an arduino installed in the robot. This robot is also can detect obstacle and avoidance using sonar. It transmits phonetic pulses in its surroundings and for the echoes from the objects nearby that lie within its working range, hence detects obstacles. The robot is installed with Omni wheel which is a special function of this robot. This Omni wheel that provides easy $360^{\circ}$ movement propel with rotational and sideways maneuverability. The outcome of the project is a combination of embedded computing and programming.
\end{abstract}

Keyword: Obstacle detection, voice recognition, Omni wheel, android, human- robot interaction. 


\section{Contents}

Acknowledgement $\ldots \ldots \ldots \ldots \ldots \ldots \ldots \ldots \ldots \ldots \ldots \ldots \ldots \ldots \ldots \ldots \ldots \ldots \ldots$

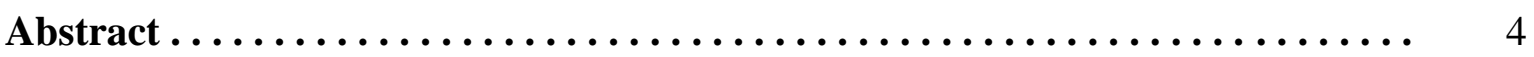

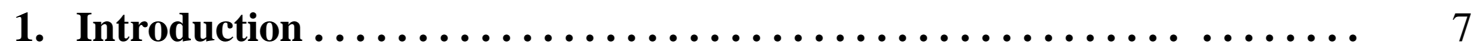

1.1 Motivation.$\ldots \ldots \ldots \ldots \ldots \ldots \ldots \ldots \ldots \ldots \ldots \ldots \ldots \ldots \ldots \ldots \ldots \ldots \ldots$

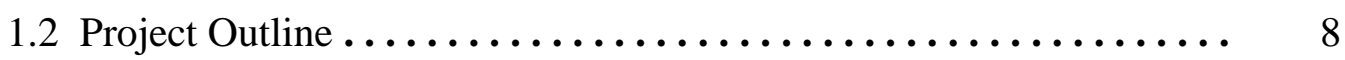

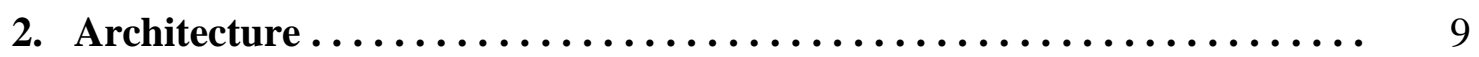

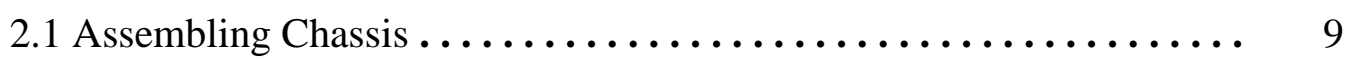

2.2 Assembling Process $\ldots \ldots \ldots \ldots \ldots \ldots \ldots \ldots \ldots \ldots \ldots . \ldots \ldots \ldots$

3. Implementation $\ldots \ldots \ldots \ldots \ldots \ldots \ldots \ldots \ldots \ldots \ldots \ldots \ldots \ldots \ldots \ldots \ldots$

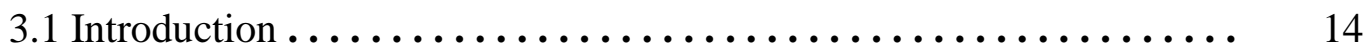

3.2 Mechanical Implementation $\ldots \ldots \ldots \ldots \ldots \ldots \ldots \ldots \ldots \ldots \ldots \ldots$

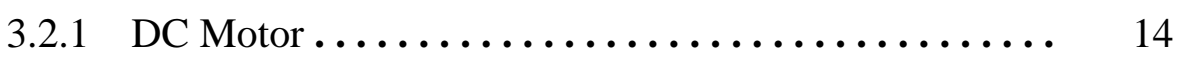

3.2.2 Omni Wheel $\ldots \ldots \ldots \ldots \ldots \ldots \ldots \ldots \ldots \ldots \ldots$

3.2.3 Ultrasonic Sensor ................... 17

3.2.4 Servo Motor .................... 18

3.3 Electrical Implementation $\ldots \ldots \ldots \ldots \ldots \ldots \ldots \ldots \ldots \ldots \ldots . \ldots \ldots$

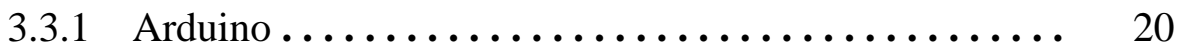

3.3.2 DC Motor Controller ................ 22

3.3.3 Bluetooth Communication .............. 23

3.3.4 System Circuit Design ................ 25

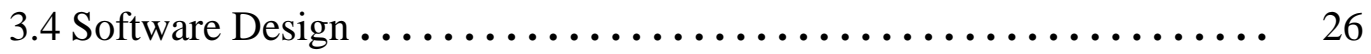

3.4.1 Arduino Software $\ldots \ldots \ldots \ldots \ldots \ldots \ldots \ldots \ldots$

3.4.2 Android App Design .................. 27

3.5 Control Implementation.$\ldots \ldots \ldots \ldots \ldots \ldots \ldots \ldots \ldots \ldots \ldots \ldots$

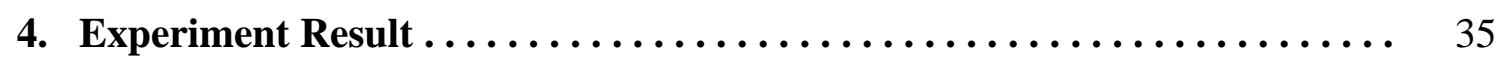

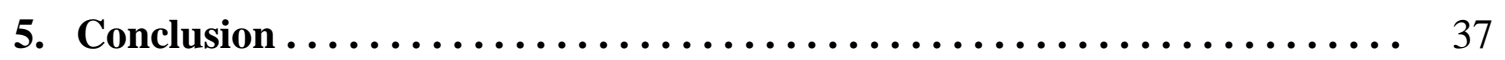

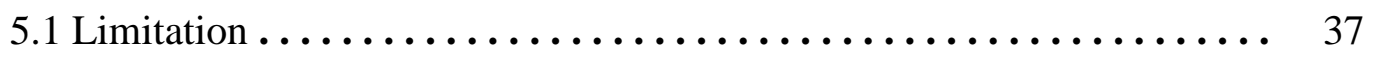

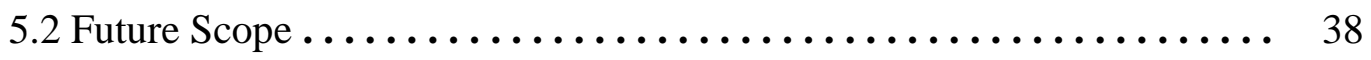

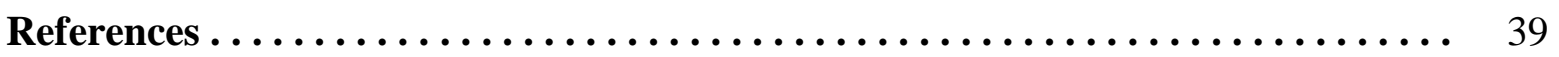




\section{List of Figures}

Figure 1: Chassis and Body Parts $\ldots \ldots \ldots \ldots \ldots \ldots \ldots \ldots \ldots \ldots \ldots \ldots \ldots \ldots$

Figure 2: Chassis installed with motors $\ldots \ldots \ldots \ldots \ldots \ldots \ldots \ldots \ldots \ldots \ldots \ldots \ldots$

Figure 3: Connecting Omni wheel to the motor................... 11

Figure 4: Base on chassis to support the bin $\ldots \ldots \ldots \ldots \ldots \ldots \ldots \ldots \ldots \ldots \ldots \ldots$

Figure 5: Servo motor bottom of the bin for mouth function $\ldots \ldots \ldots \ldots \ldots \ldots \ldots$

Figure 6: Servo motor on top for ultrasonic sensor movement $\ldots \ldots \ldots \ldots \ldots \ldots \ldots \ldots$

Figure 7: Ultrasonic sensor mounted on servo motor $\ldots \ldots \ldots \ldots \ldots \ldots \ldots \ldots \ldots$

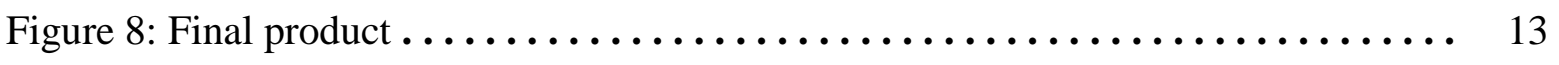

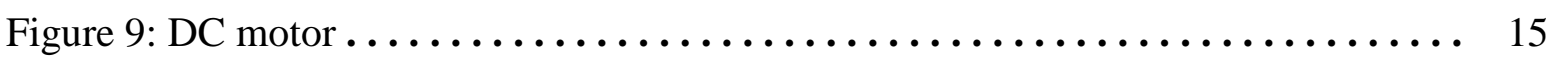

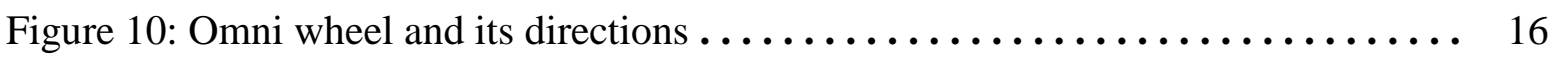

Figure 11: Ultrasonic Sensor and its simple description $\ldots \ldots \ldots \ldots \ldots \ldots \ldots \ldots \ldots$

Figure 12: Servo Motor ............................. 19

Figure 13: Arduino Uno board $\ldots \ldots \ldots \ldots \ldots \ldots \ldots \ldots \ldots \ldots \ldots \ldots \ldots \ldots \ldots \ldots \ldots$

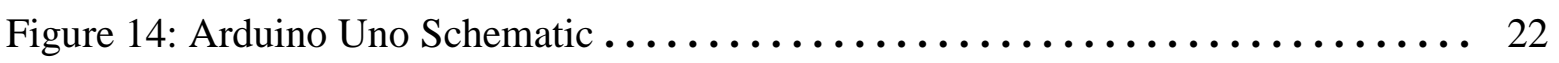

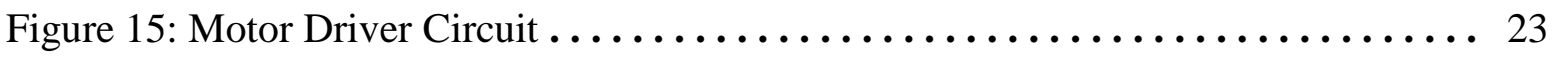

Figure 16: Bluetooth Module ........................... 24

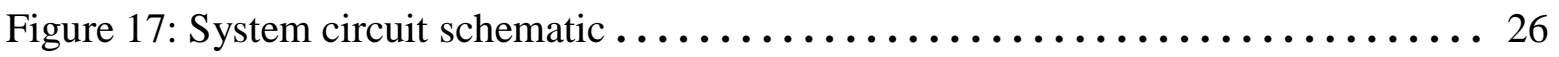

Figure 18: Arduino Software $\ldots \ldots \ldots \ldots \ldots \ldots \ldots \ldots \ldots \ldots \ldots \ldots \ldots \ldots \ldots \ldots$

Figure 19: Block Diagram of MIT App Inventor. ................. 28

Figure 20: App Inventor Designer . . . . . . . . . . . . . . . . . . . . 29

Figure 21: App inventor blocks editor $\ldots \ldots \ldots \ldots \ldots \ldots \ldots \ldots \ldots \ldots \ldots \ldots \ldots \ldots \ldots \ldots \ldots \ldots \ldots$

Figure 22: Block diagram of control system $\ldots \ldots \ldots \ldots \ldots \ldots \ldots \ldots \ldots \ldots \ldots \ldots \ldots$

Figure 23: Connect button and set Bluetooth device................. 32

Figure 24: Speak function. ............................... 33

Figure 25: Control flow diagram $\ldots \ldots \ldots \ldots \ldots \ldots \ldots \ldots \ldots \ldots \ldots \ldots \ldots \ldots \ldots$

Figure 26: Performance of accuracy for English speaking younger adults $\ldots \ldots \ldots \ldots 36$

Figure 27: Performance of accuracy for English speaking older adults $\ldots \ldots \ldots \ldots \ldots$ 


\section{Chapter 1}

\section{INTRODUCTION}

\subsection{Motivation:}

Google Now has become a central part of the Android operating system by introducing new functions and capabilities with every candy-flavored iteration. We can't even think of our lives without android application now-a-days. It made a revolutionary change in the world today. Millions of multiple devices are working through Google Android OS. Everyone around the world can use this Google Android development policy. There are many developers who are developing this application daily. Though this application has much popular functionality, Voice Recognition is one of them and preferred form of communication with the robot is speech [1]. Over the past few years it can be seen that speech recognition technology have been made an intense advances. Another most interesting possibility of this development is the combination with ARDUINO which is a microprocessor, also known as tiny computer. In robotics, Ultrasonic or sonar sensors are widely used for range finding for indoor and outdoor applications. It transmits phonetic pulses in its surroundings and for the echoes from the objects nearby that lie within its working range. Within some recent years mobile robotic system has been developed for selfexplanatory navigation. There are various applications in electronics and robotics about ultrasonic sensor. Like as detection and avoidance, mapping and navigation, object recognition and identification. While working with these sensors need to be very careful though sonar sensors have different practical limitations. Sonar is mainly used for three applications in robotics [7]. The first is obstacle detection and avoidance, where the range to 
the closest object is measured by detecting the first echo. In this paper we describe about a home robot which can be beneficial for home tasks through Google voice command on android device, in addition it can detect obstacles using sonar. The hardware of this robot is inspired from the robot R2D2 from the movie Star Wars.

\subsection{Project Outline:}

The objection of building this robot is for home tasking staring with garbage collection. The report is organized such a way to give detailed information about to build a robot which can be controlled using particular voice command on android devices and can identify obstacles using ultra sonic sensor. This report is divided in three major parts 1.Hardware, 2.Software and 3.Elecrical. First part includes assembling the robot parts, body, Omni wheels, electric circuit design and control of mouth of storage bin. Second part contains software programming of android using MIT app inventor 2 and arduino microcontroller. Electric part has been described about the connection among the electrical parts used in this project. Moreover, the limitation, results and discussion are also described in end of this paper. 


\section{Chapter 2}

\section{ARCHITECTURE}

\subsection{Assembling Chassis:}

Main frame of the robot is made of aluminum plate. It is a very simple design consists of three DC motors and Omni wheels, screws, one RFL wastage-bin, acrylic, servo motors and plastic board. The frame of the robot has been made in triangle shape and each angel is $60^{\circ}$. Motors has are screwed inside each angular point of the frame such a way that shafts are on outside of the frame where Omni wheels are attached. Then plastic board has been used for the base of the wastage-bin and circuit board. Bottom of the wastage-bin a servo motor has been attached to drive the mouth of the bin and on the top another servo motor has been attached for the movement of the ultrasonic sensor. Acrylic board has been used to mount the bin on the frame of the robot. 

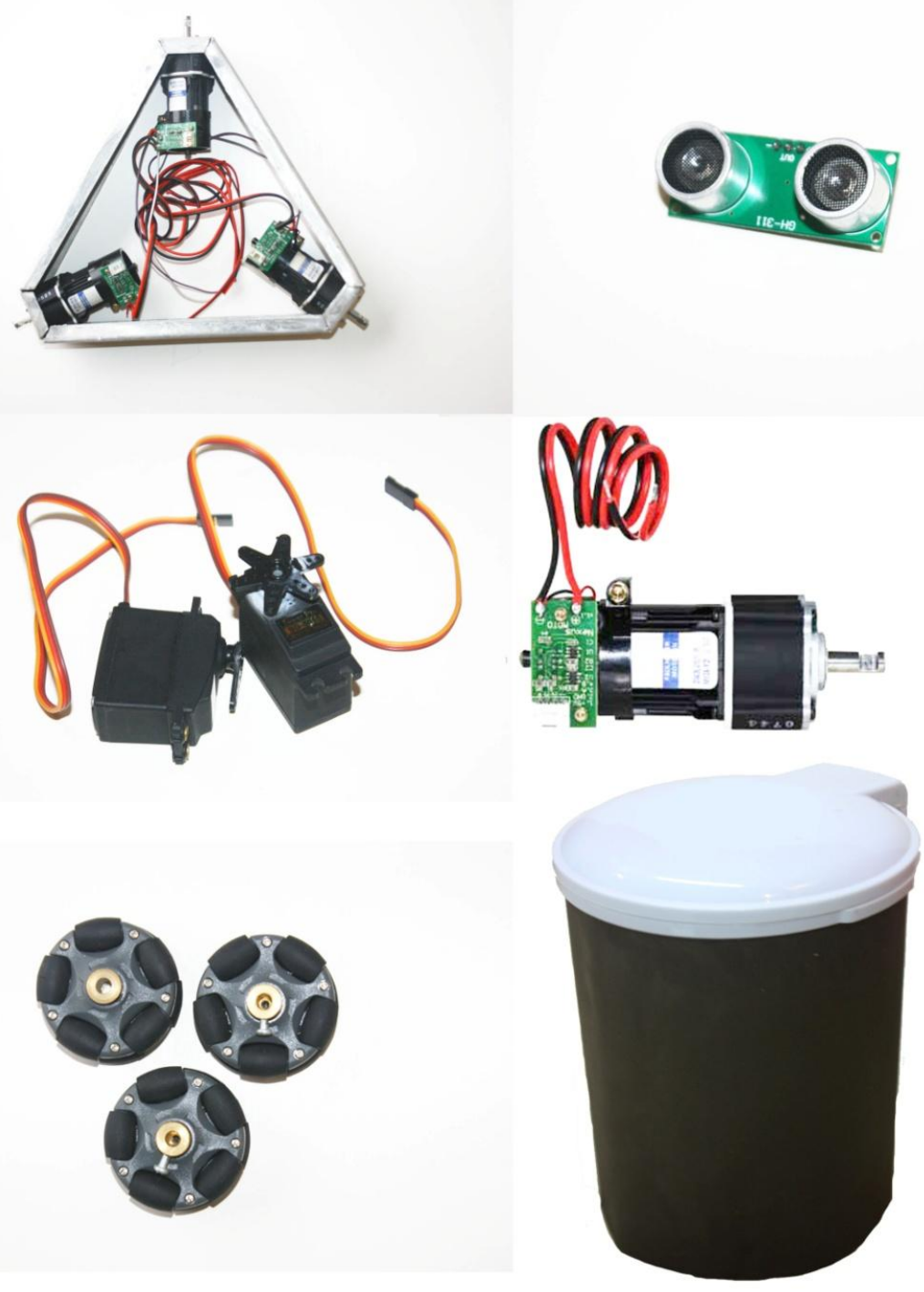

Figure 1: Chassis and Body Parts.

\subsection{Assembling Process:}

The figures below show the process of assembling. 


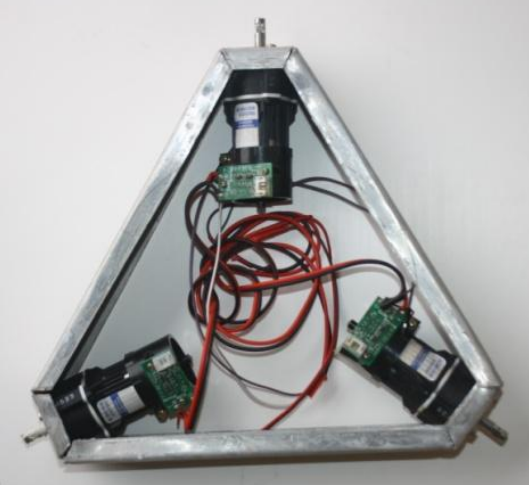

Figure 2: Chassis installed with motors.

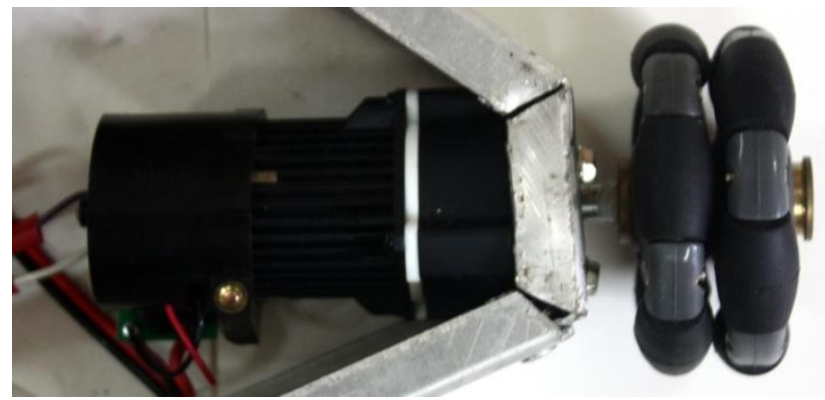

Figure 3: Connecting Omni wheel to the motor.

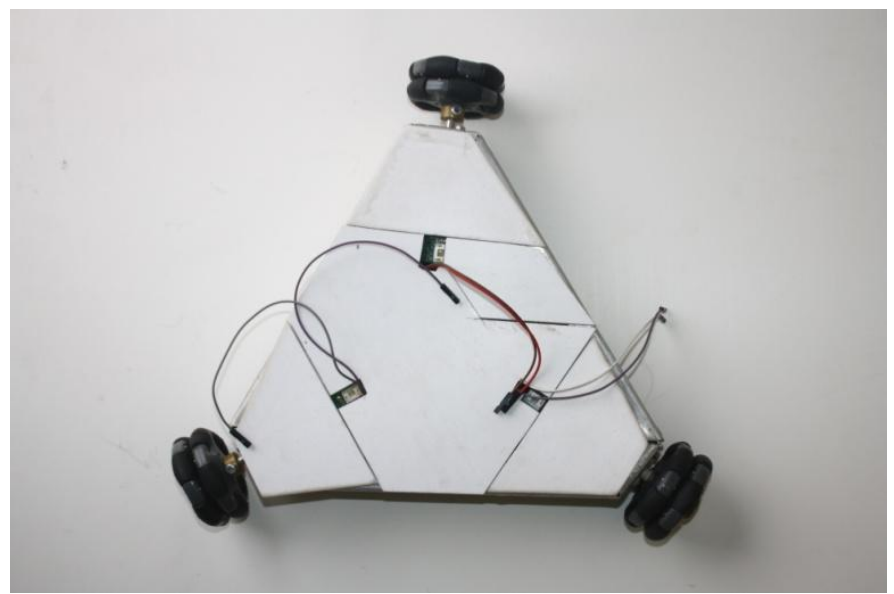

Figure 4: Base on chassis to support the bin. 


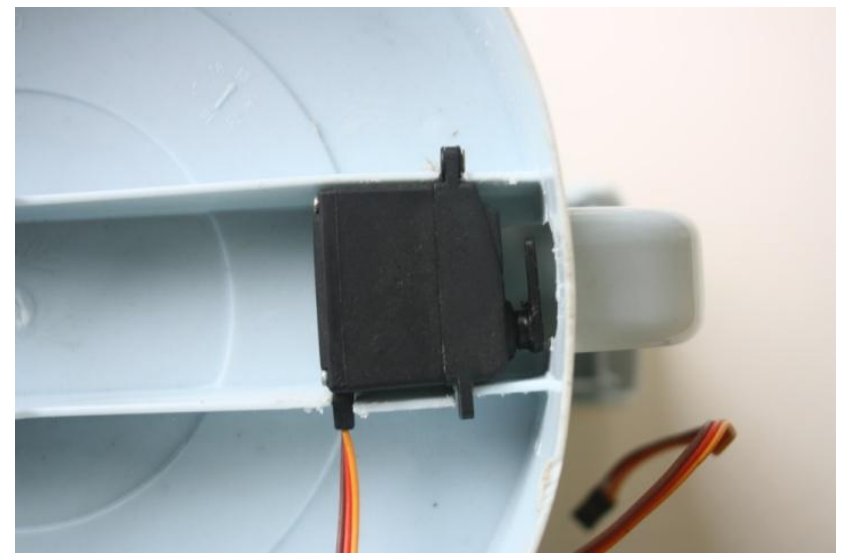

Figure 5: Servo motor bottom of the bin for mouth function.

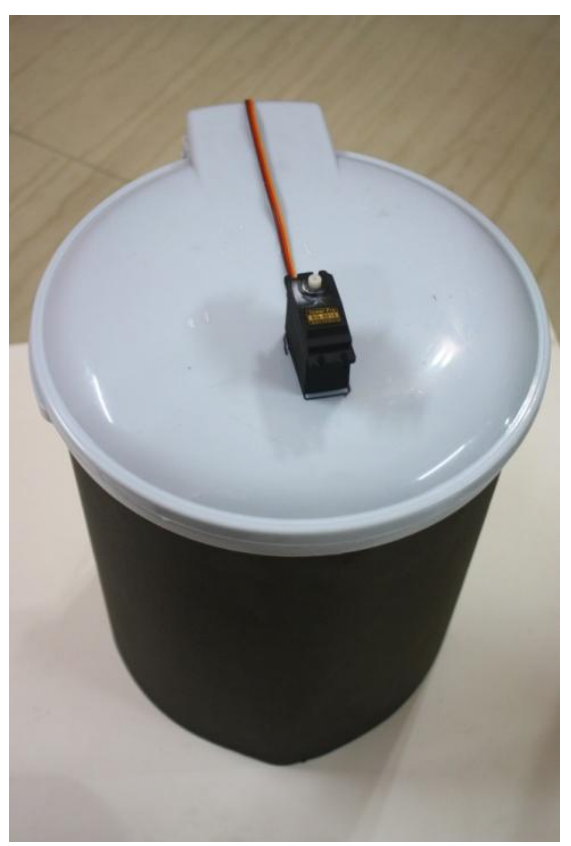

Figure 6: Servo motor on top for ultrasonic sensor movement.

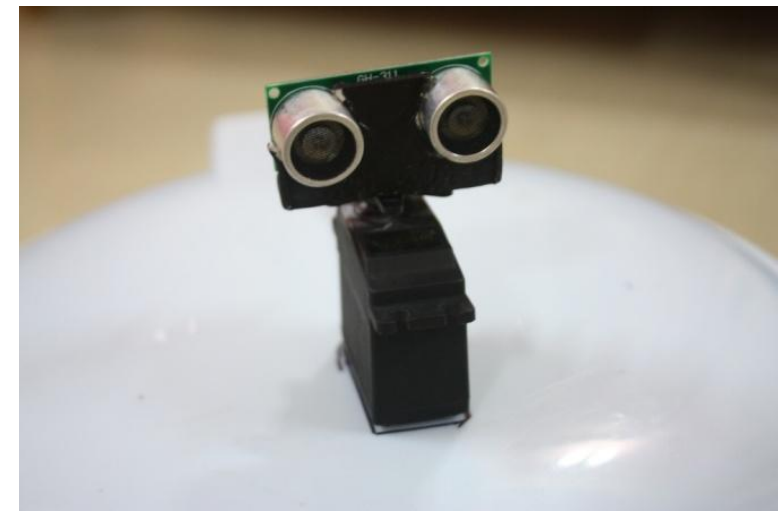

Figure 7: Ultrasonic sensor mounted on servo motor. 


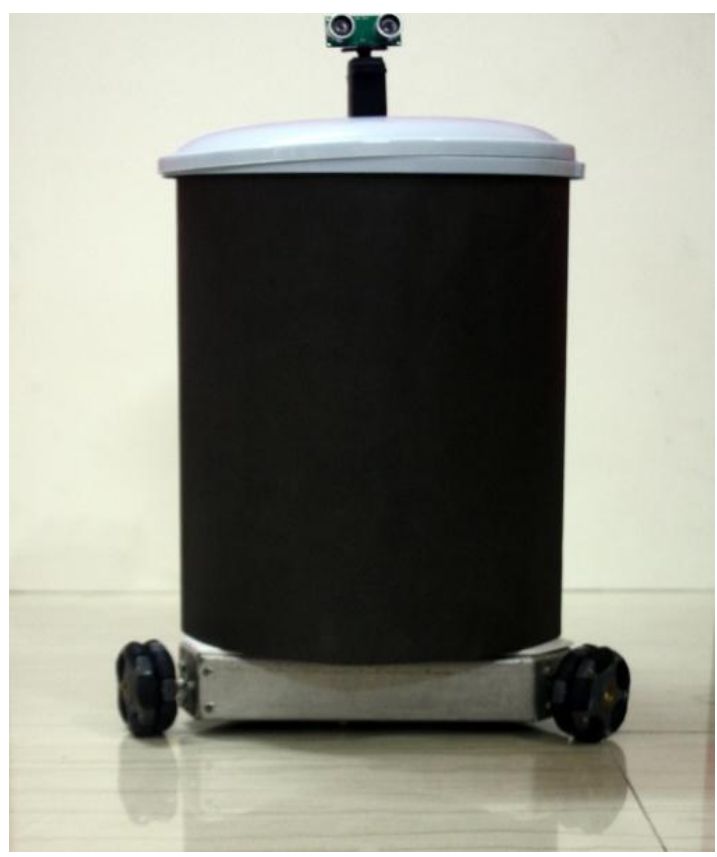

Figure 8: Final product. 


\section{Chapter 3}

\section{IMPLIMENTATION}

\subsection{Introduction:}

In this chapter we have covered the mechanical part, electrical part and software part. Different component were used in mechanical and electrical part such as DC motors, ultrasonic sensor, Bluetooth module, servo motors control. In software part the programming procedure is described of android and arduino. Control, power and communication are also described in this chapter.

\subsection{Mechanical implementation:}

\subsubsection{DC motor:}

We have used FAULHABER MICROMOTOR series 2342 in our thesis project. It is a coreless DC-Micro motor, based on System Faulhaber® technology. The motor is very light in weight and compact. It has the high limpidity motion and control applications. This motor is very useful because of having high power density and extremely low current consumptionlow starting voltage. Due to low inertia, low inductance coil it has highly dynamic performance. These motors feature brushes manufactured of a sintered metal graphite material and a copper commutator. This ensures that the commutation system can withstand more power. The heart of these Flat DC-Micro motors is the ironless rotor made up of three flat self supporting coils. The rotor coil has exceptionally low inertia and inductance and rotates in an axial magnetic field. Motor torque can be increased by the addition of an 
integrated reduction gear head. This also reduces the speed to fit the specifications in the application. It has a speed up to $7000 \mathrm{rpm}$ and its precision gear head gives a torque up to 16 $\mathrm{mNm}$. This motor is both clockwise and counterclockwise operational and the direction of the motor is reversible. Positive voltage on + terminal gives clockwise rotation on motor shaft. Three DC motors has been used to give a stable movement of the robot.

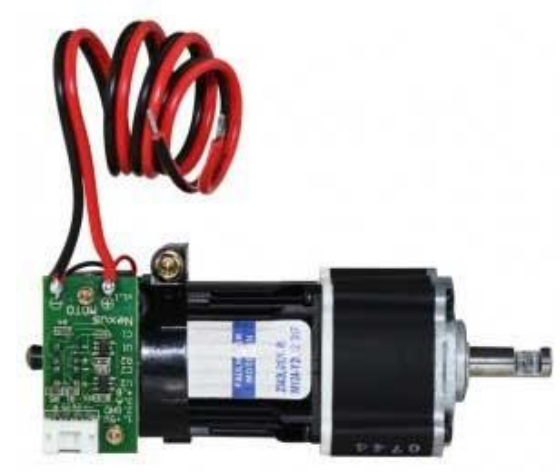

Figure 9: DC motor.

\section{DC motor Specification:}

Diameter: $30 \mathrm{~mm}$

Total length (exclude shaft): $85 \mathrm{~mm}$

Shaft diameter: $6 \mathrm{~mm}$

Shaft length: $35 \mathrm{~mm}$

Torque: $1.72 \mathrm{Nm}$

Speed: $8100 \mathrm{rpm} / 120 \mathrm{rpm}$ (after gear reduction) 


\subsubsection{OMNI WHEEL:}

Omni directional wheel refer to the ability of a system to move rapidly in any direction from any configuration. It has vast advantages over mobility environments congested with static and dynamic obstacles and narrow walkways [2] [3]. Mobile robot that be made up of Omnidirectional wheel has the ability to perform various difficult movements. We have used latest design of 58mm Omni directional robot wheel, It's useful as they roll freely, The $58 \mathrm{~mm}$ plastic Omni wheel is a robust, durable and double row wheel that provides easy $360^{\circ}$ movement propel with rotational and sideways maneuverability. Using of Omni wheel on robot can be able to forward/backwards and rotation without changing its orientation. Omni wheels are installed each corner of the base of the robot.

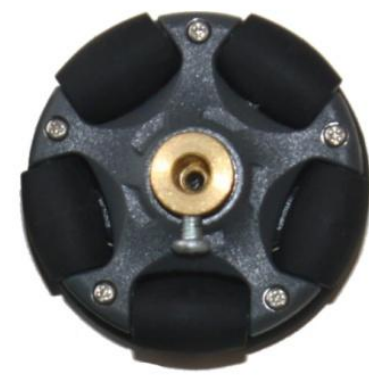

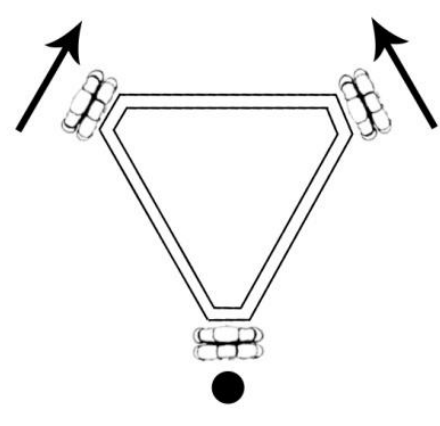

Forwards

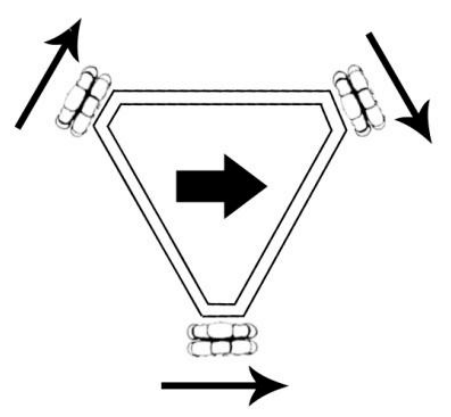

Side way

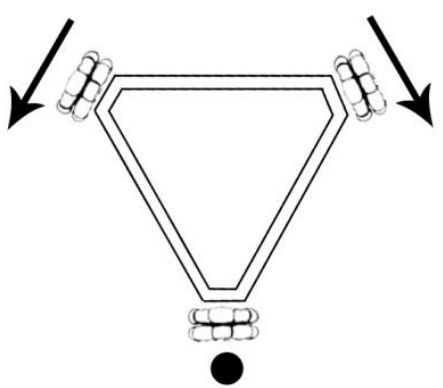

Backwards

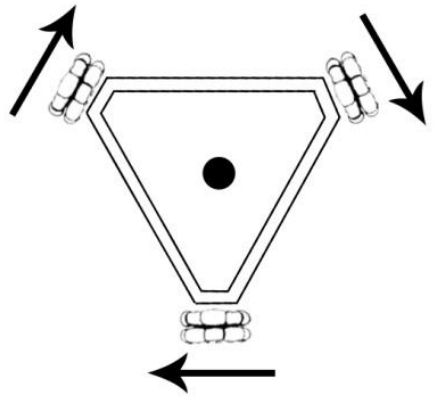

360 degree rotation

Figure 10: Omni wheel and its directions. 


\section{Specifications of Omni Wheel:}

Body Roller Color: Black

Wheel Diameter: $58 \mathrm{~mm}$

Roller Diameter: $13 \mathrm{~mm}$

Body Material: Nylon

Roller Material: Nylon+PE

Load capacity: $3 \mathrm{KG}$

Net weight: $60 \mathrm{~g}$

\subsubsection{Ultrasonic sensor:}

The GH-311 ultrasonic Motion sensor provides precise, non-contact distance measurements from about $2 \mathrm{~cm}$ ( 0.8 inches) to 3 meters (3.3 yards). It is very easy to connect to microcontrollers such as the BASIC Stamp, SX or Propeller chip, requiring only one I/O pin.

The GH-311 sensor works by transmitting an ultrasonic (well above human hearing range) burst and providing an output pulse that corresponds to the time required for the burst echo to return to the sensor. By measuring the echo pulse width, the distance to target can easily be calculated. This sonar sensor is used to detect any obstacle any pass away the obstacles. This sonar is mounted on head in front side and it works as an eye [4]. This ultrasonic sensor gives the robot ability to roaming indoors without any collision with other objects. 

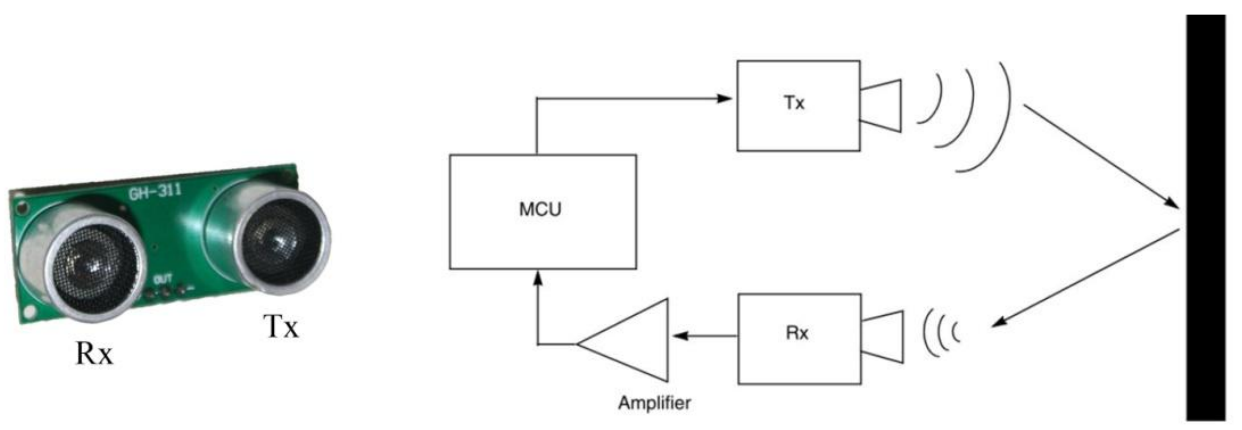

Figure 11: Ultrasonic Sensor and its simple description.

\section{Ultrasonic Technical Specifications:}

Power Voltage: DC 6-12V

Quiescent current: Less than 2mA

Output Level: High 5V

Output Level: Low 0V

Sensing Angle: no greater than $15^{\circ}$

Sensing distance: $2 \mathrm{~mm}-3 \mathrm{~m}$

\subsubsection{Servo Motors:}

As ultrasonic sensor is placed in front of the robot, it cannot detect obstacles from its other side. So a servo motor is mounted to move ultrasonic sensor horizontally from fixed point. 
Thus the ultrasonic sensor can sense obstacle from both its left and right side. Servo motor's shaft can be positioned to specific angular position by sending signal from the controller. Servo motor can be controlled directly from arduino board as it has built-in control circuit, not external driver or controller is needed. Servo motor, used in this robot can rotate its shaft approximately 180 degrees. This servo motor is well powerful than its size with torque about $11 \mathrm{~kg}-\mathrm{cm}$ at voltage $4.8 \mathrm{~V}$. Another servo motor has been used to open and close the mouth of the bin.

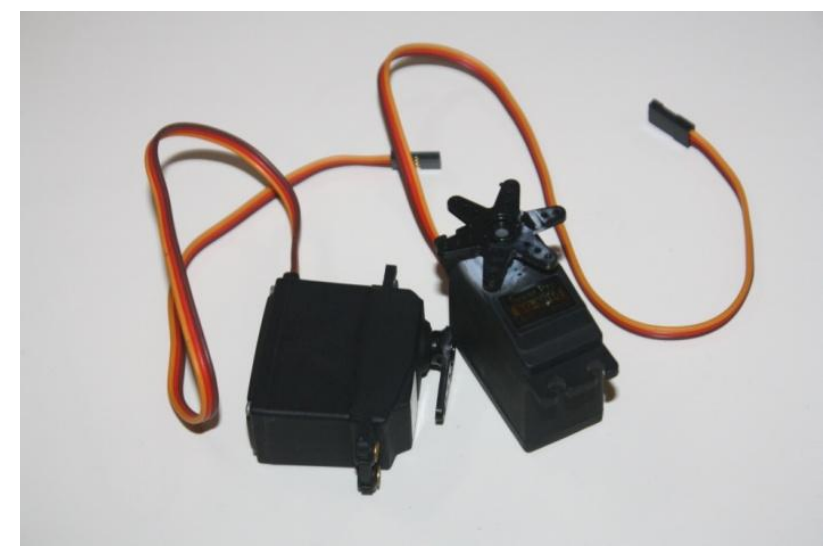

Figure 12: Servo Motor.

\section{Servo Motor Specifications:}

Modulation: Analog

Torque: 4.8V:111.1 oz-in (8.00 kg-cm); 6.0V:152.8 oz-in (11.00 kg-cm)

Speed: $4.8 \mathrm{~V}: 0.17 \mathrm{sec} / 60^{\circ} ; 6.0 \mathrm{~V}: 0.14 \mathrm{sec} / 60^{\circ}$

Weight: $1.34 \mathrm{oz}(38.0 \mathrm{~g})$

Dimensions: Length: 1.58 in (40.1 mm); Width: 0.80 in (20.3 mm); Height:1.70 in (43.2 mm)

Motor Type: 3-pole 
Gear Type: Plastic

Rotation/Support: Dual Bearings

Rotational Range: $180^{\circ}$

Pulse Cycle: $20 \mathrm{~ms}$

Pulse Width: 600-2400 $\mu$ s

\subsection{Electrical Implementation:}

We have focused on the use of Arduino in this chapter which is the core processor of the project that controls the robot by sending signal. Moreover we have already designed a circuit that will control the DC motors.

\subsubsection{Arduino:}

"Arduino is an open-source electronics prototyping platform based on flexible, easy to use hardware and software. It's intended for artists, designers, hobbyists, and anyone interested in creating interactive objects or environments."

The project Arduino first began in 2005 at Interaction Design Institute Ivrea (IDII). Massimo Banzi (Massimo Banzi 2012) co-founder of Arduino worked in IDII as an associate professor who supposed to teach the students about modern interactive design in an inexpensive way. So that everybody can bear it without facing any obstacles in their work. After that with the help of a Columbian student named Hernando Barragán (Barragan Studio 2012) they make it 
simpler and easier. At the end they make it prototype and this is how the Arduino has been given birth by them.

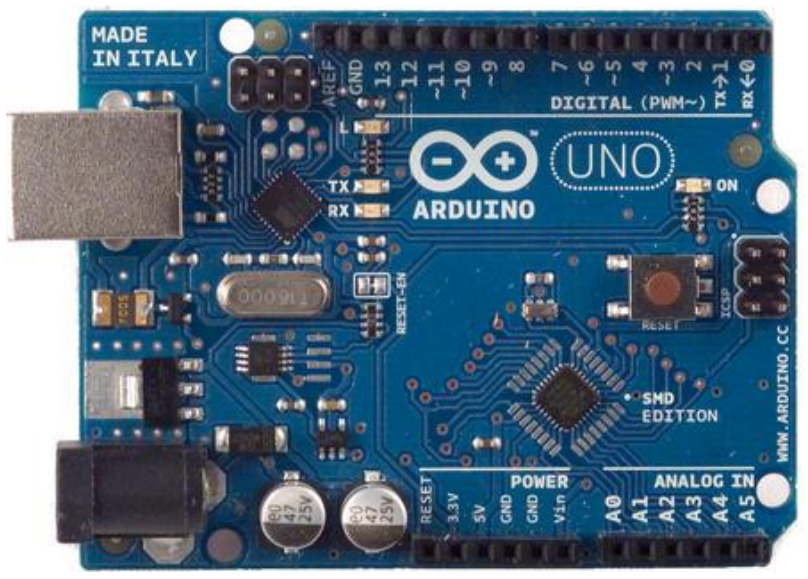

Figure 13: Arduino Uno board.

As we mentioned before that Arduino is an open-source physical computing platform which is based on easy-to-use hardware and software. It is resourceful in its innovation. This product is famous in the electronic professionals because of its simplicity which can make enthusiastic changes in electronic computing in the future.

In this project we have used the hardware Arduino Uno R3. This is microcontroller based. 5v power is needed to operate it. It has the limitation of input voltage of $6-20 \mathrm{~V}$ and recommended input voltage is 7-12 V. It consists of 14 digital input/output of which 6 provide PWM output and 6 analog input pins. It comes with a USB connector, a power jack, an ICSP(In-Circuit Serial Programming) header and a reset button. It has a flash memory of 32KB (ATmega328) of which $0.5 \mathrm{~KB}$ used by boot loader. SRAM is of $2 \mathrm{~KB}$ and EEPROM of $1 \mathrm{~KB}$. The clock speed has been set to $16 \mathrm{MHz}$. 


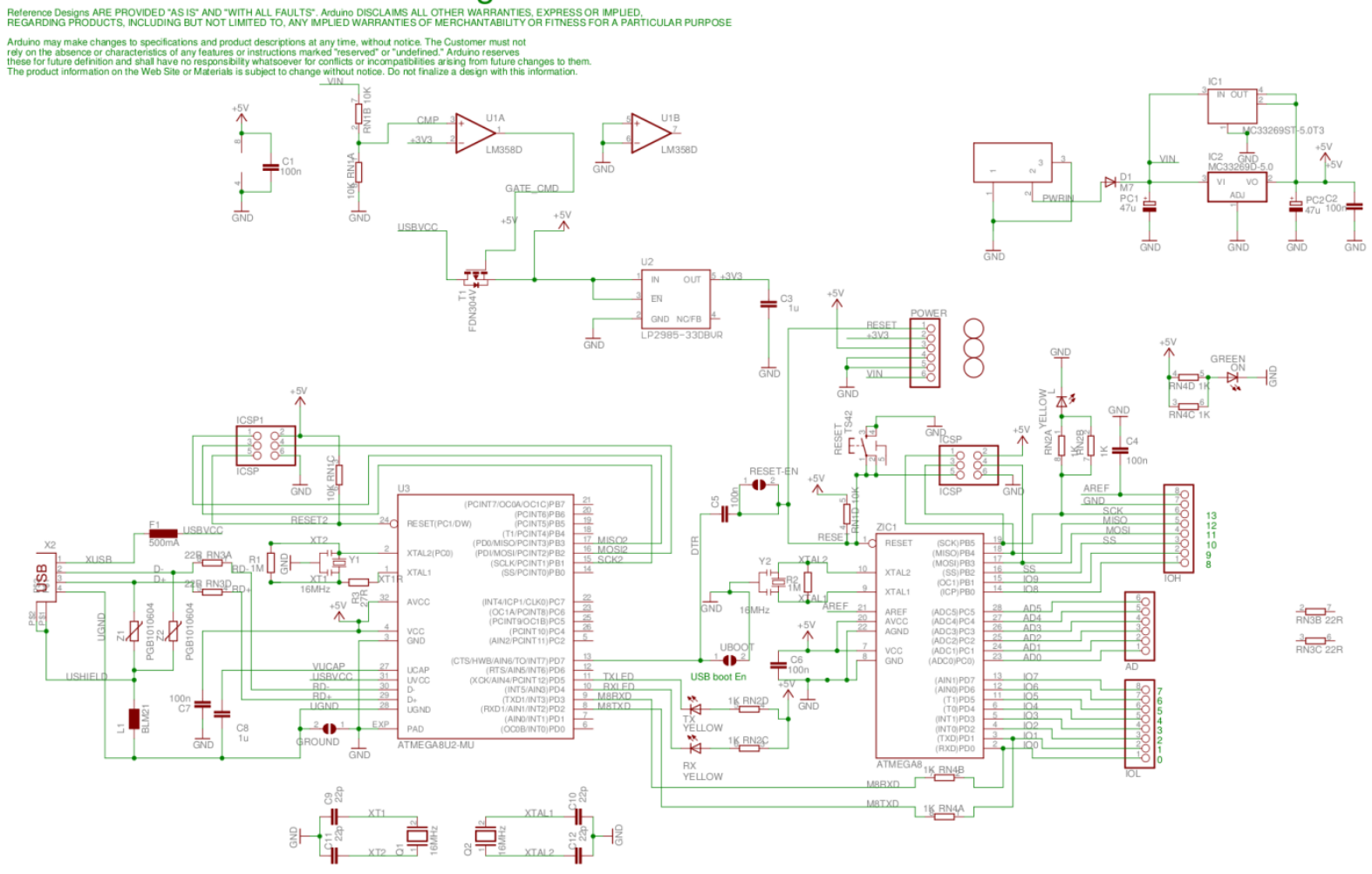

Figure 14: Arduino Uno Schematic.

This is the mother board of the robot. DC motor controller, ultrasonic sensor, servo motors and Bluetooth module are directly connected in this board and controlled by it.

\subsubsection{DC motor controller:}

We have used L293D which is a DC motor driver chip to control the motors in bi-directional. L293D chip contain two full H-bridges which means each chip can control to DC motors bidirectionally. So we have used two L293D to control the motors. 


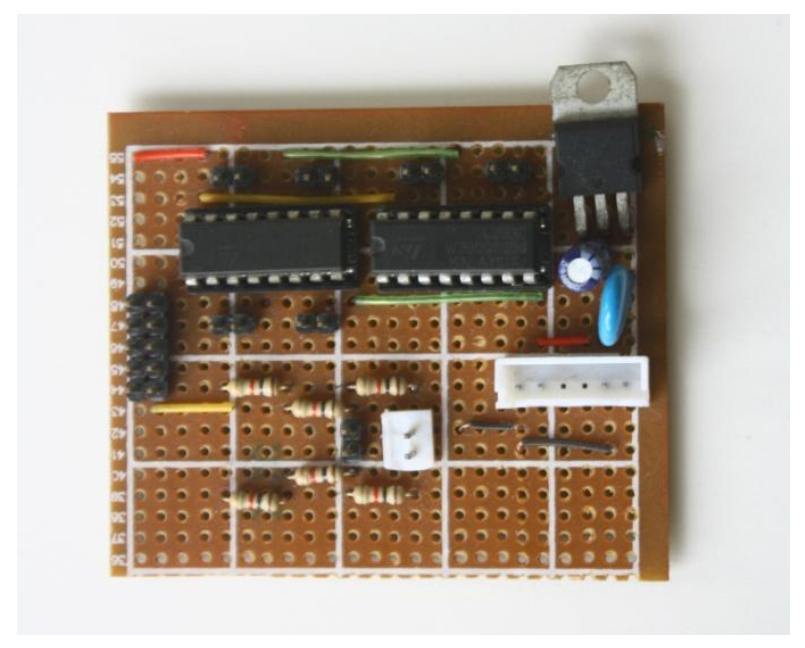

Figure 15: Motor Driver Circuit.

\subsubsection{Bluetooth Communication:}

Bluetooth is a technology which is reduced the need of wire to communicate among different devices and it is simple, secure and small in size. This technology is a major innovation in the world of technology hence it has made communication robust, easy and low cost. Almost every device such as mobile, computer has been using this technology. Any Bluetooth enable devices can easily connect to communicate with each other wirelessly within a limited area $[5]$.

This technology is allowed both link layer and application layer which allow to data and voice communications. Minimum range of Bluetooth is about 30 feet. It is a technology operating at industrial, scientific and medical (ISM) unlicensed band of 2.4 to $2.485 \mathrm{GHz}$. It uses spread spectrum, frequency hopping and full duplex signal at a nominal rate of 1600 hops/sec.

The Bluetooth module is used in this project is HC-05 which is works as a serial (TX/RX) pipe. It can communicate from any Bluetooth enable device at transferring data rate of 9600 
bps to 115200 bps. This Bluetooth module is arduino capable. We have been used this module to arduino to communicate with any Bluetooth enable devices such as android based cell phone for voice command. This module can operate at $3.3 \mathrm{~V}$ to $6 \mathrm{~V}$ and all signal pins on the remote unit are $3 \mathrm{~V}-6 \mathrm{~V}$ tolerant.

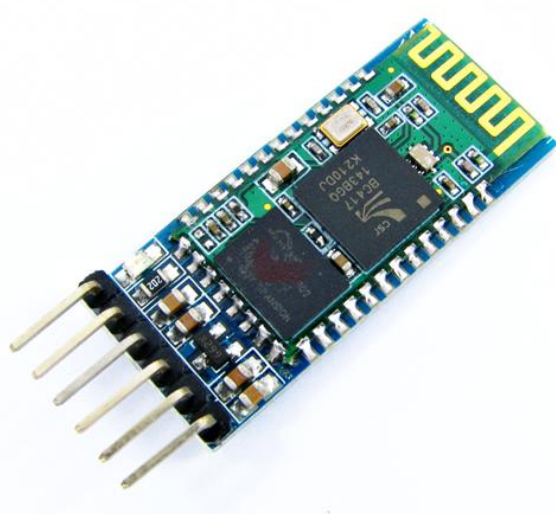

Figure 16: Bluetooth Module.

\section{Bluetooth Specification:}

Bluetooth protocol: Bluetooth Specification v2.0+EDR

Frequency: $2.4 \mathrm{GHz}$ ISM band

Modulation: GFSK (Gaussian Frequency Shift Keying)

Emission power: $\leq 4 \mathrm{dBm}$, Class 2

Sensitivity: $\leq-84 \mathrm{dBm}$ at $0.1 \%$ BER

Speed: Asynchronous: 2.1Mbps (Max) / 160 kbps, Synchronous: 1Mbps/1Mbps

Security: Authentication and encryption 
Profiles: Bluetooth serial port

Power supply: +3.3VDC 50mA

Working temperature: $-20 \sim+75$ Centigrade

Dimension: $26.9 \mathrm{~mm}$ x $13 \mathrm{~mm}$ x $2.2 \mathrm{~mm}$

\subsubsection{System Circuit Design:}

This circuit design enable to communicate with hardware part has been used for this project. The procedure of designing this circuit involves the arrangement of arduino, DC motor driver, Bluetooth module, sonar and servo motors together.

Receiver (RX) pin and transmitter pin (TX) of Bluetooth is connected to arduino pin 11 and 10 accordingly as those pins have been defined as serial port with jumper wire. Pin 2, 7 and 9, 13 of L293d are connected to pin 3, 4 and 6, 7 for motor 1 and motor2 accordingly. Pin 9 and 13 from another L293d is connected to arduino pin 8 and 9 accordingly. Servo motor signal pin for panning the sonar and operate the mouth of the bin is connected to arduino pin 12 and 13 accordingly. Power pin of Bluetooth, servo motors and ultrasonic sensor are connected to $5 \mathrm{~V}$ pin Arduino and the ground pin is connected to the Arduino ground pin. 


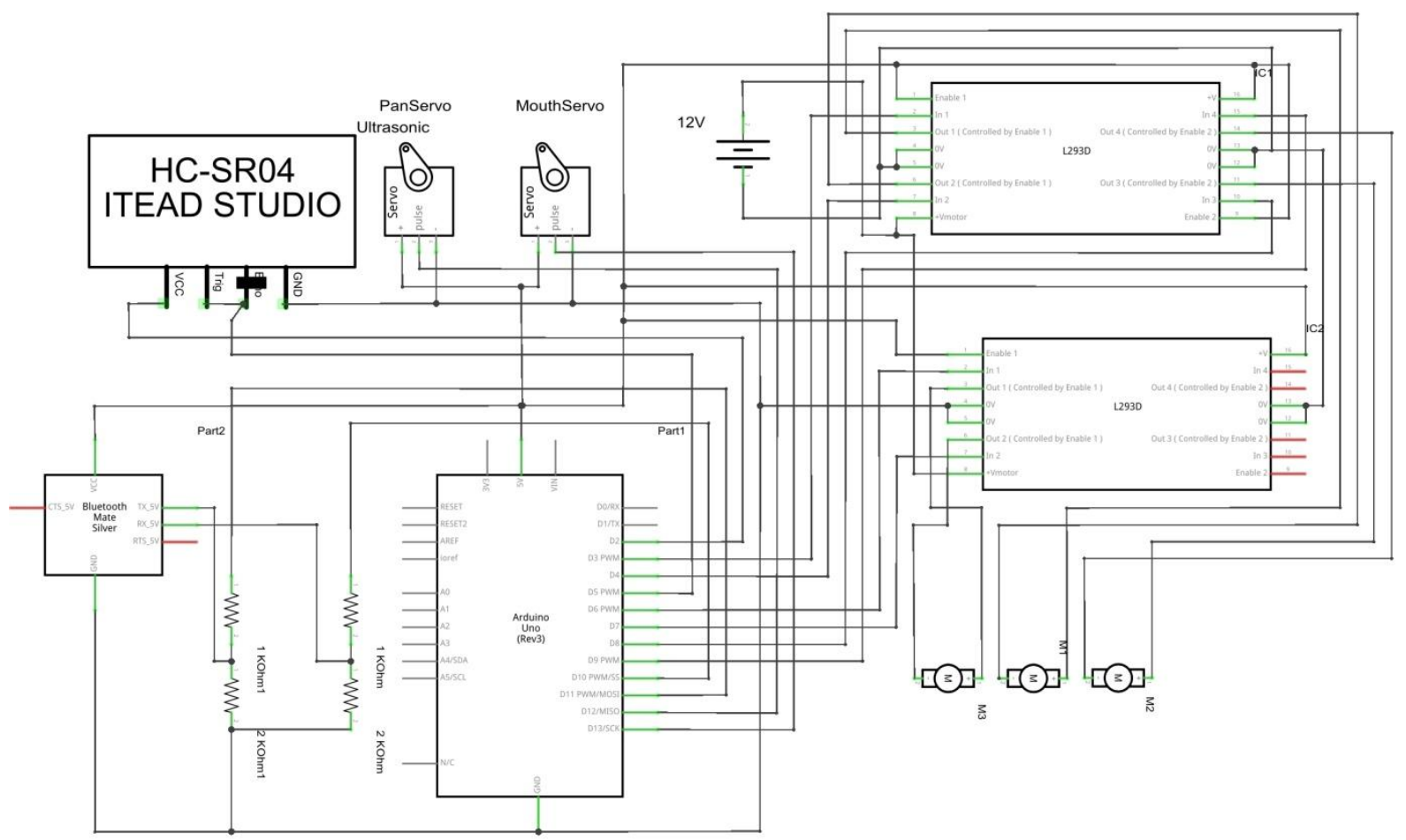

fritzing

Figure 17: System circuit schematic.

All the connections are made with the wires from the breadboard to Arduino.

\subsection{Software Design:}

\subsubsection{Arduino Software:}

Arduino board can be programmed from the Arduino software, which is available for different platforms such as Windows, Mac OSX and Linux. It is open source software, which is designed using a Java environment and is also based on processing and avr-gcc. Figure 14. Arduino Software The software allows users to write their code in C and upload to the board. The boot loader allows the uploading without the need of external hardware programmer. Thus the software is very easy to use and efficient. 


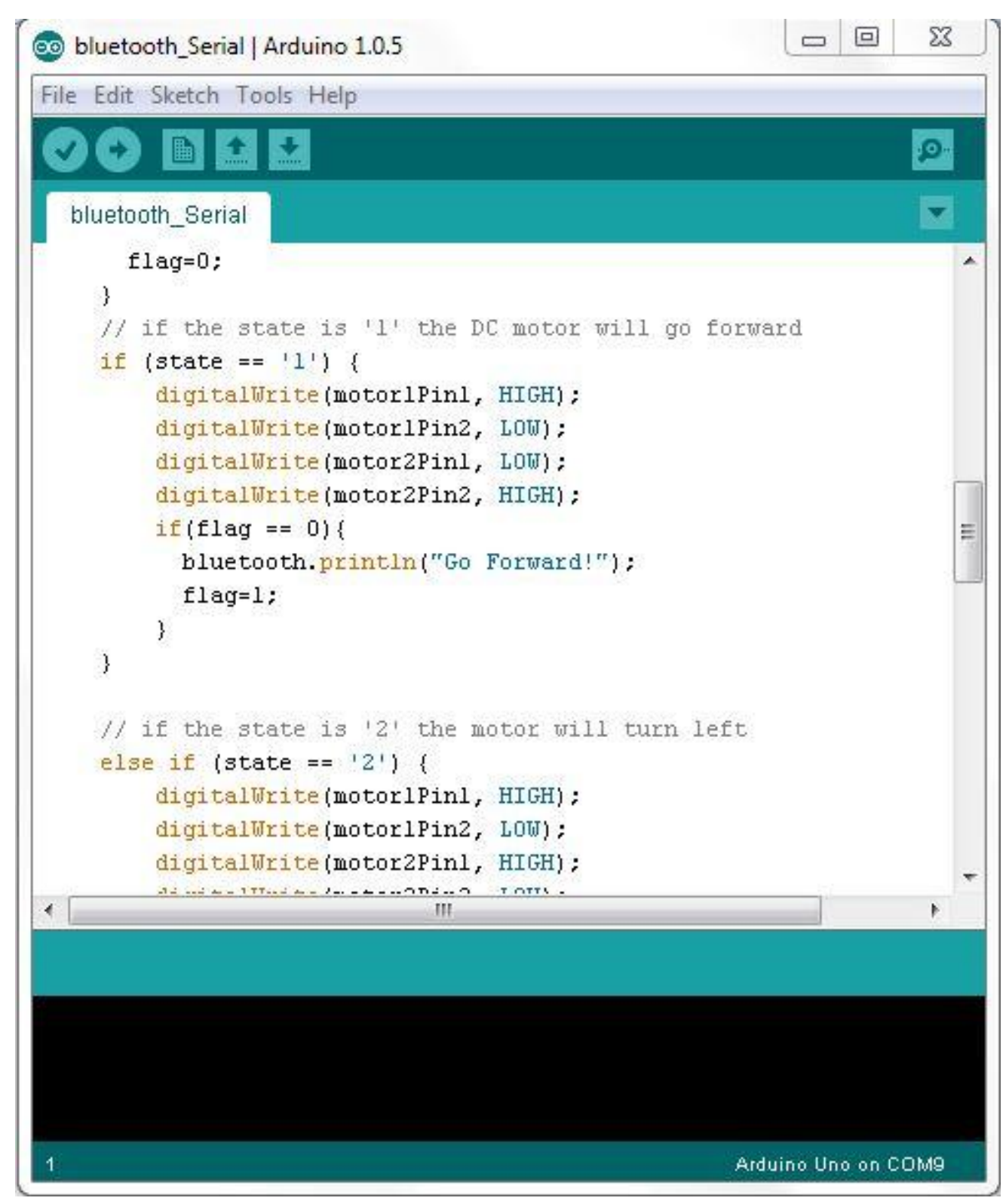

Figure 18: Arduino Software.

\subsubsection{Android App Design:}

The application for the android device has been developed using an open source web application which is originally provided by Google and maintained by Massachusetts Institute of Technology (MIT) known as MIT App Inventor. On December 6, 2013 MIT 
released App Inventor 2 and this web application has been used to develop the app for the robot.

MIT App Inventor makes android programming simpler. Limiter knowledge of programming can develop any android app through this technology. This is very simple yet effective way to develop any application for android. No heavy software installation is needed for this and this can be done just over web browser with a Google account. Processes of building application through this contain three aspects:

a. App inventor designer

b. App inventor block editor

c. An emulator or android phone

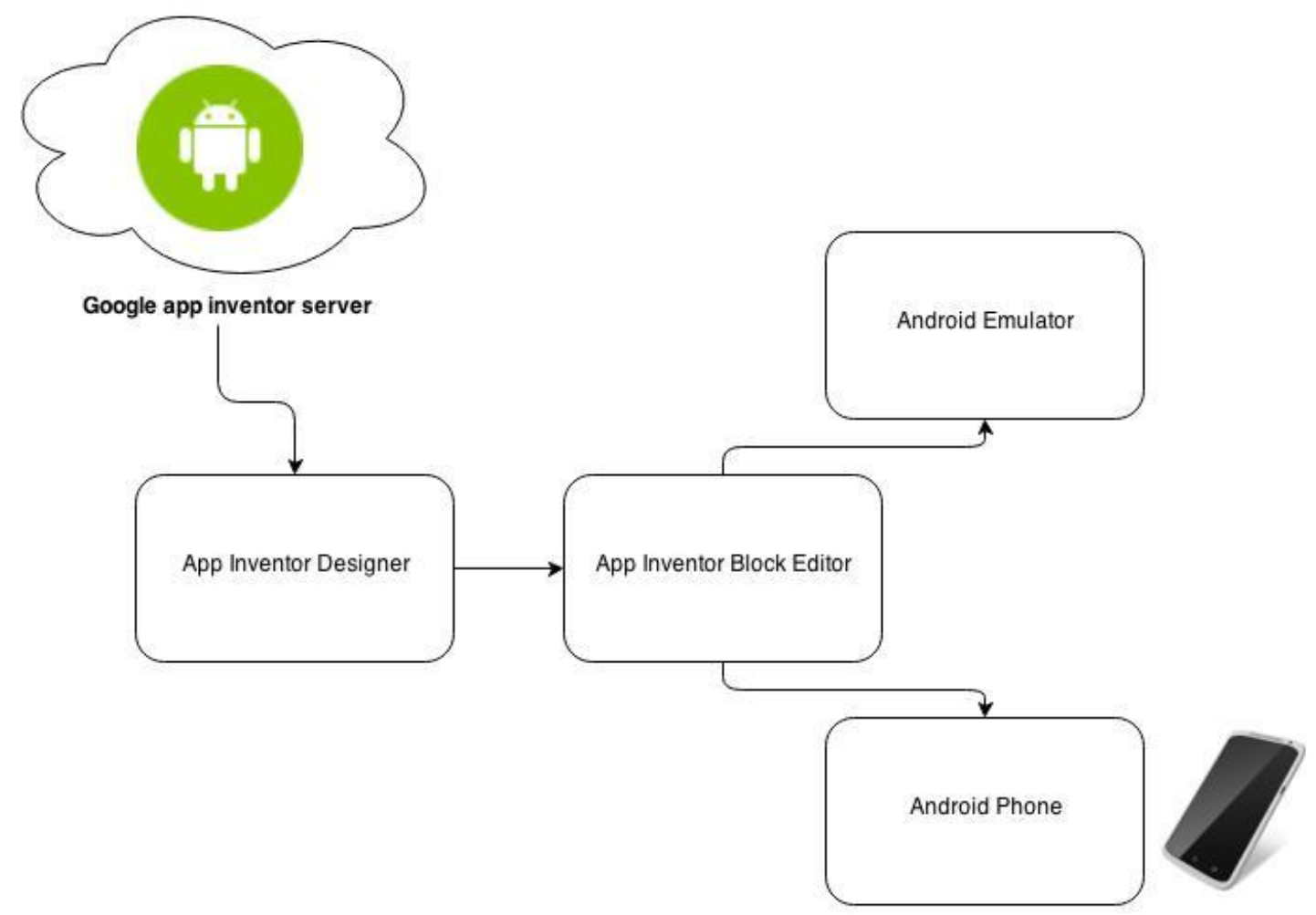

Figure 19: Block Diagram of MIT App Inventor. 


\section{App inventor designer:}

First stage to develop the app is app inventor design. In this section, we have designed the app with all the available ingredients on the web page of MIT App Inventor 2. The ingredients include screen, button, text box, image and many more. We have simply followed drag and drop process to put the desired item on screen. We have put one button to connect the speech recognizer and another to connect with Bluetooth module. Some non-visible elements like clock, Bluetooth client, speech recognizer have been added there too which is described in block editor.

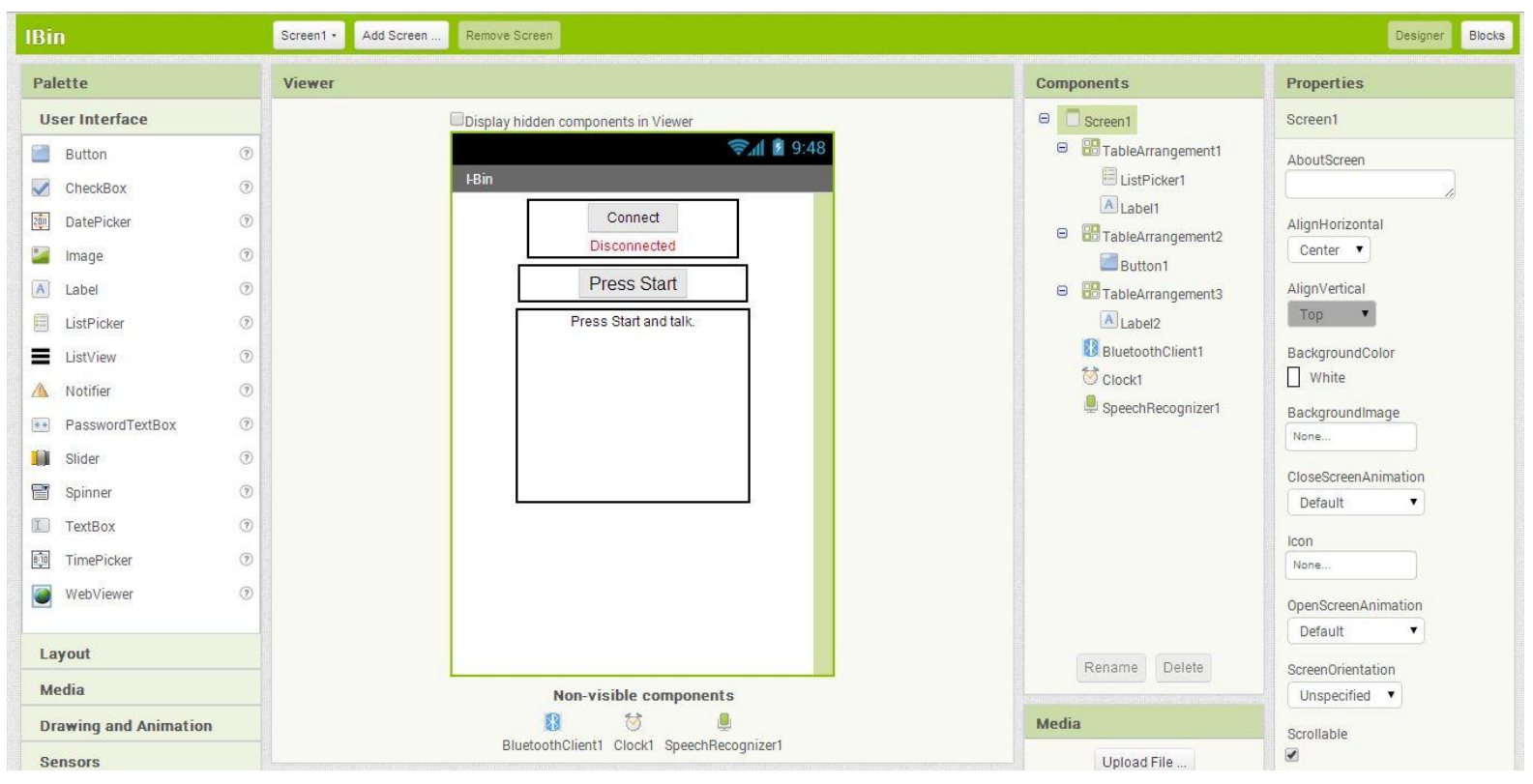

Figure 20: App Inventor Designer.

\section{App inventor block editor}

After design, we had to program the app using block editor so that our app can be functioned as desired. Block editor is also on the same web page of MIT app inventor 2. On classic app inventor we had to use java library to open the block editor but in app inventor 2 we can use 
the editor on web page. Blocks are programming code which can be dragged and connect to other block to assemble a desired function of the app. With a little logic in programming any user can combine the blocks and make the components added in Designer to function as required.

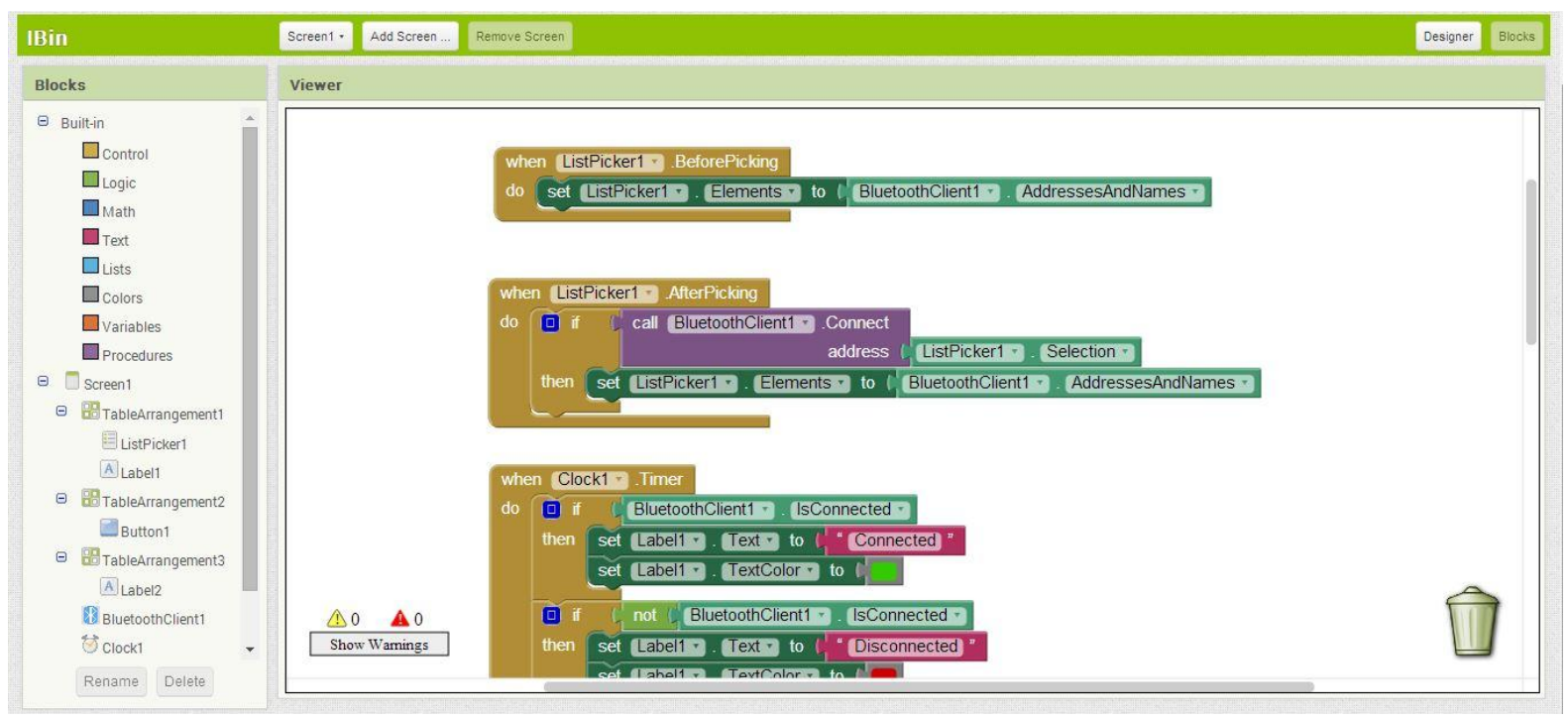

Figure 21: App inventor block editor.

\section{Android phone or emulator:}

After design and programming the app MIT app inventor 2 has a choice to test the app. App inventor gives that option to test the app without any android device using an emulator which is very similar to the real device. Through the web page user can connect to emulator installed in computer and test how the application functions in real world. User can also download the app in apk format in computer and send to android device or scanning the QR code generated by the app inventor to download the app directly to the android device and the test the app. Real time testing with directly android device is the better option for supervise the app functions. 


\subsection{Control implementation:}

I-bin is the name of the android application which has been made for this project to control the robot which was designed through MIT app inventor 2. This app is simple functions and two buttons to control the whole robot. Also this robot can operate as an obstacle detector when there is no Bluetooth connection with desired android phone.

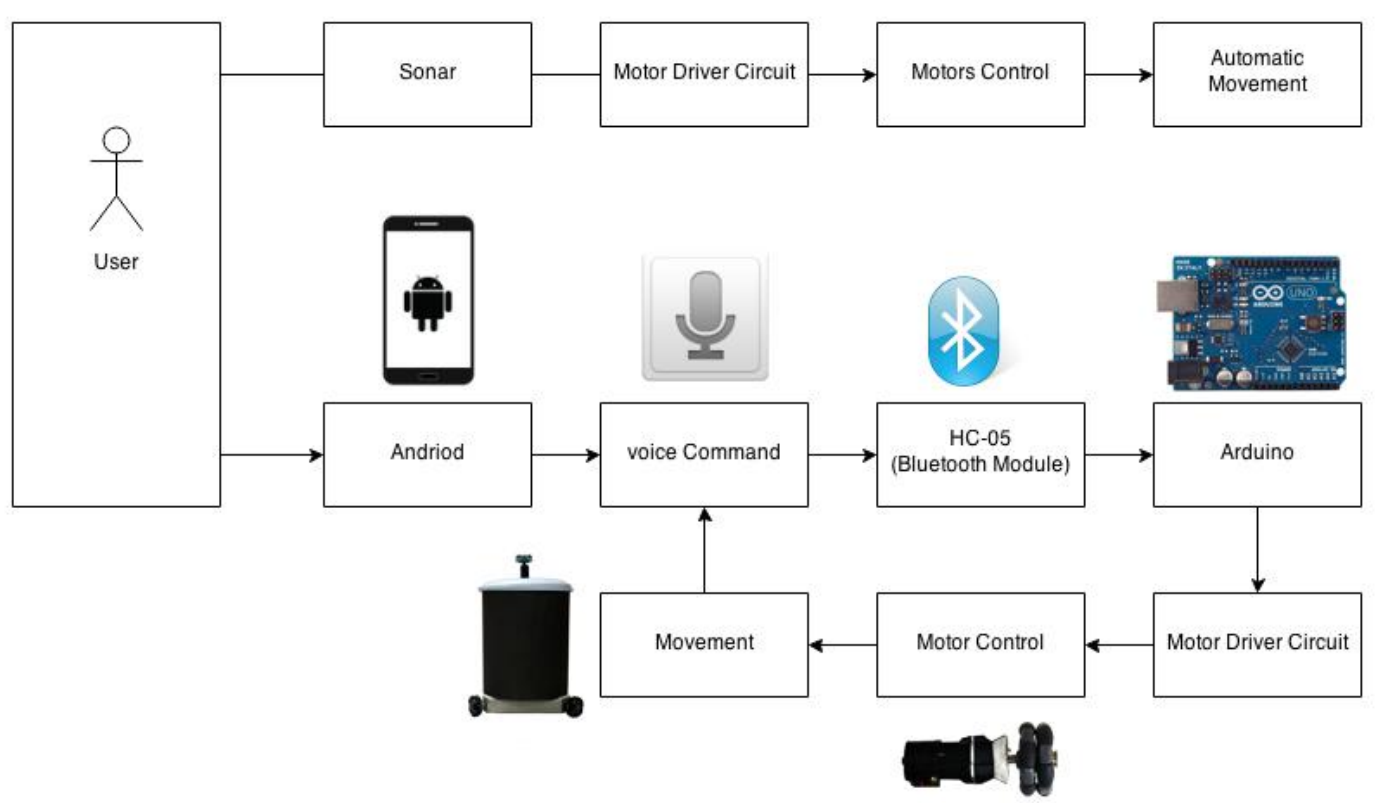

Figure 22: Block diagram of control system.

First button is for connection with Bluetooth. Taping this button a window appear with available Bluetooth connections and user have to select the desired connection, in this case the desired connection name is hc- 05 , to connect the Bluetooth module installed in arduino on the robot. Then a connection is build between android device and the robot. 
Another button is for voice command button. This button allows controlling the robot with voice command. This button activates the Google speech and users are asked to give command which will give direction to robot. There are five commands to control the robot which are 'Right', 'Left', 'Forward' to give directions to the robot and 'Open', 'Close' to open and close the mouth of the bin.

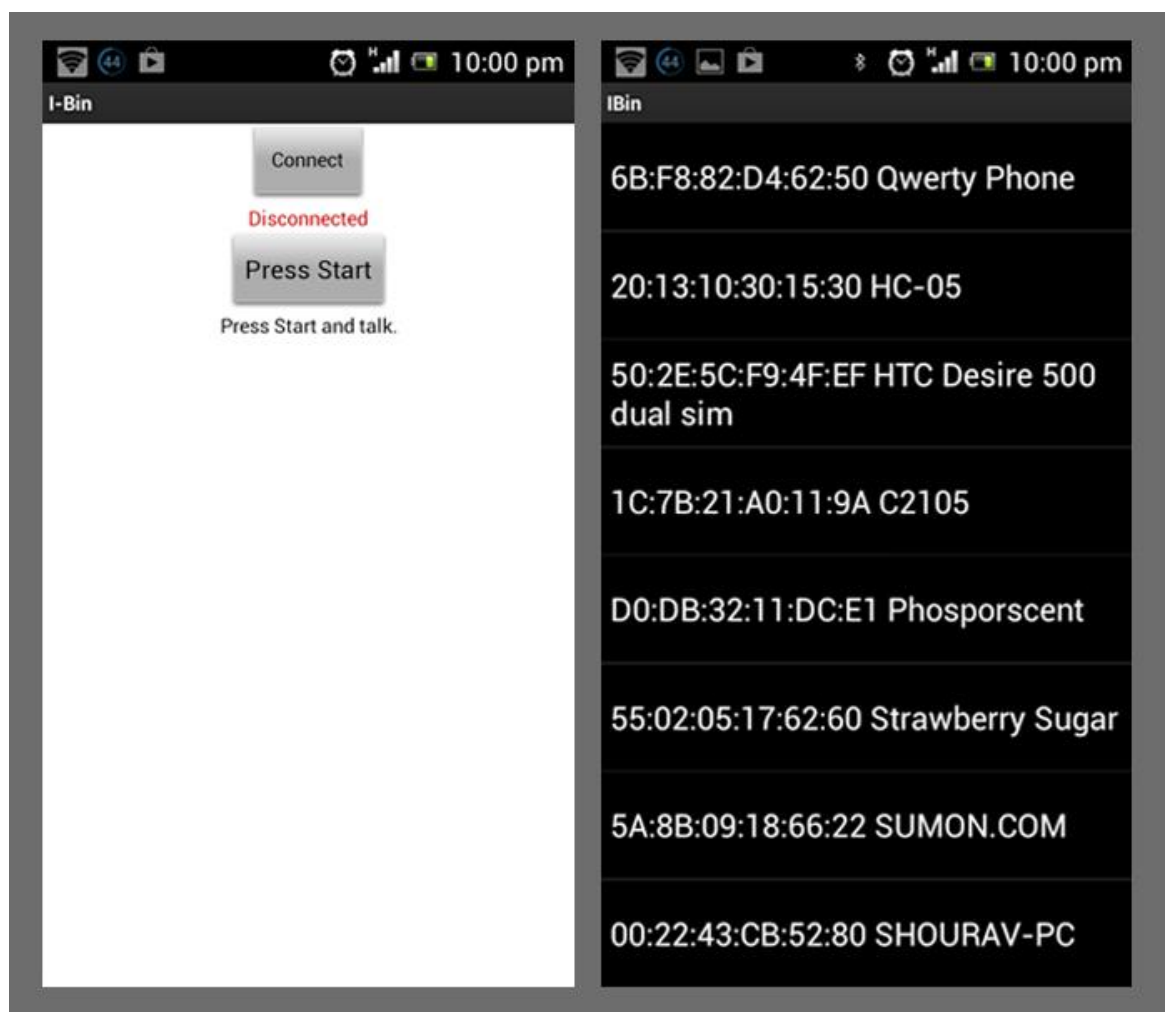

Figure 23: Connect button and set Bluetooth device. 


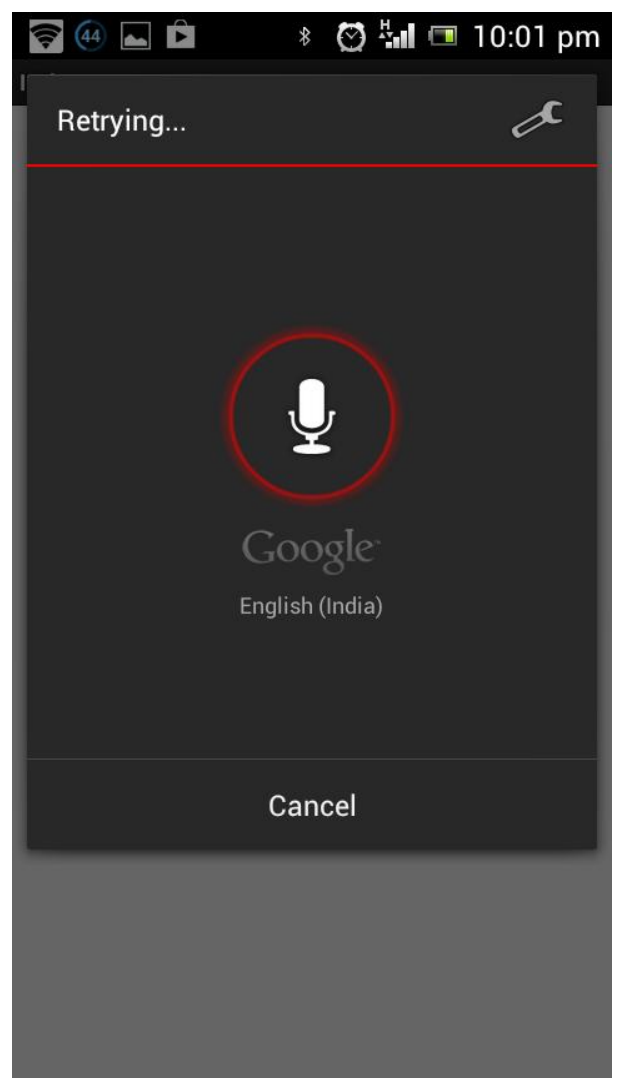

Figure 24: Speak function.

When Bluetooth serial connection is not available the robot works as an obstacle detection robot using ultrasonic sensor. Once the robot detects an object where the distance forward is greater than the danger threshold, the path is clear so our program tells the robot to move forward. Otherwise the robot will turn left, the robot will rotate to that clearer path and start heading in that direction. If the left side is also blocked then the robot will turn right. 


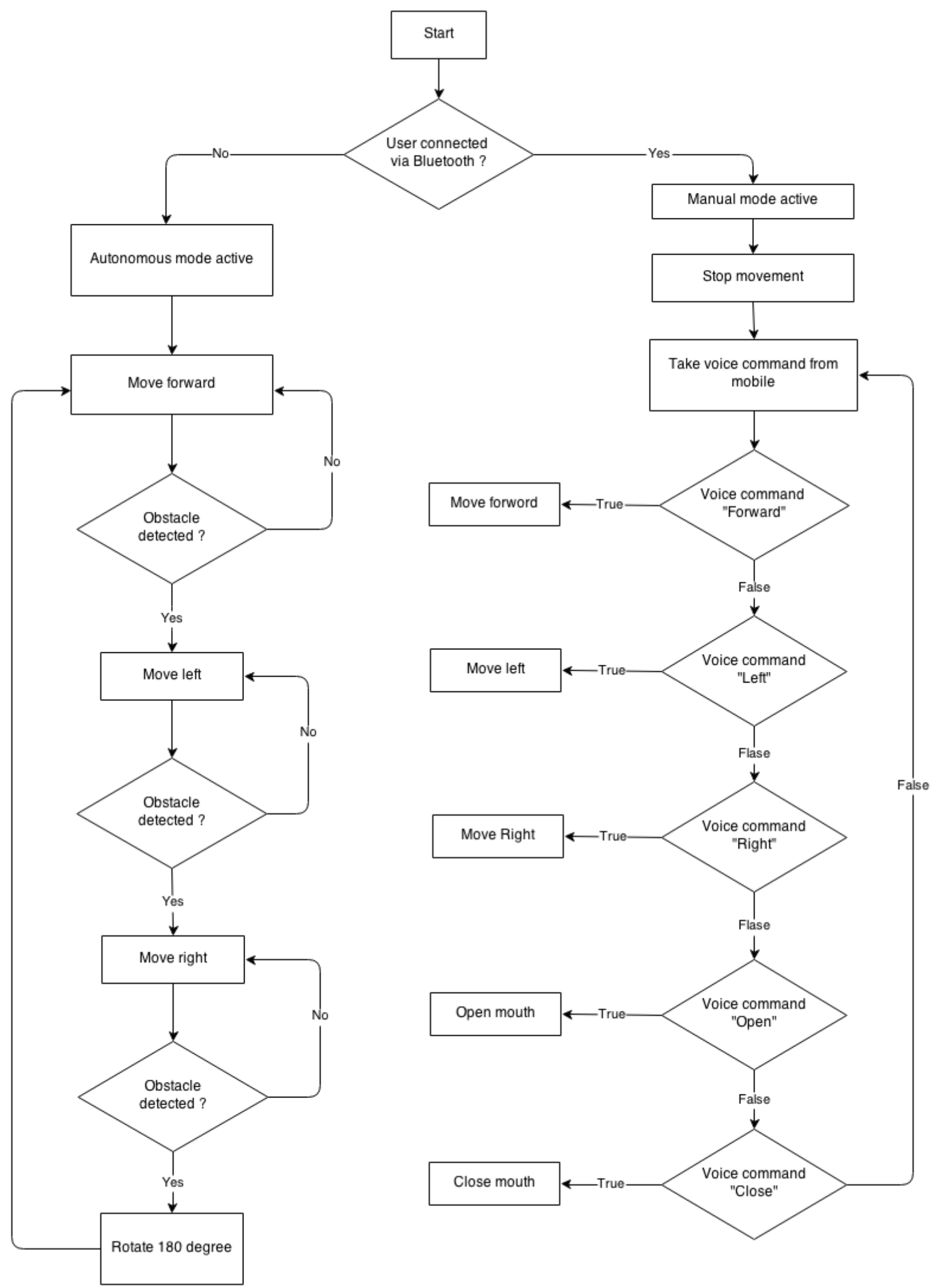

Figure 25: Control flow diagram. 


\section{Chapter 4}

\section{EXPERIMENTAL RESULT}

Several experiments were conducted to make the robot mechanism smoothly. First of all the ultrasonic sensor was tested to check the robot can detect obstacle. We had used DYPME007TX ultrasonic sensor in robot. But later we had to change the model to GH-311 because the older model communicates with the arduino via serial port also known as USART or UART. And we also have to use that serial port with Bluetooth module. So, eliminate that collusion we select GH-111 ultrasonic sensor as it is very easy to connect to microcontrollers such as the BASIC Stamp, SX or Propeller chip, requiring only one I/O pin.

Then next experiment was conducted to test the accuracy of android Google speech. We had selected few younger adults and older adults to give command the robot through our designed application on android. Starting result was $74.25 \%$ accurate in average when the language was selected English (UK or US). Accuracy has been increased about $90 \%$ when we had selected English (India) the voice search language. Women had 5\% higher per description word accuracy than men; while not statistically significant in this study; a similar

difference was reported in [6]. Fig. 26 represents the performance accuracy for English speaking younger people who are used US/UK and India accent. Again, Fig. 27 represents the performance accuracy for English speaking older people who are used US/UK and India accent. 


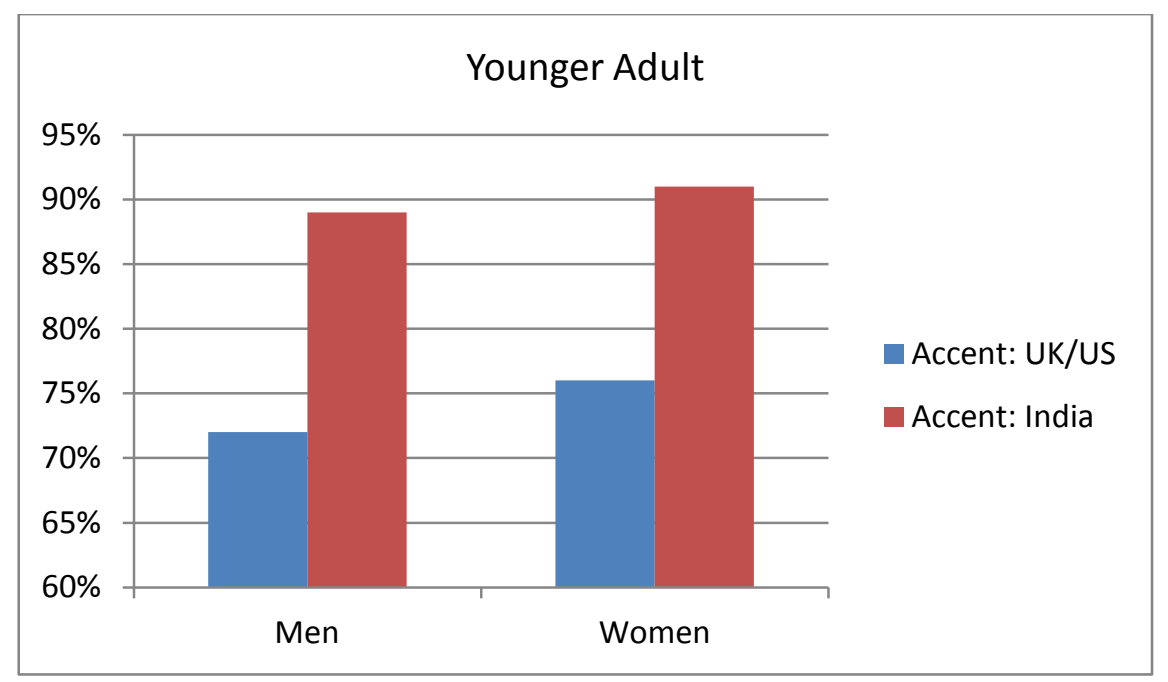

Figure 26: Performance of accuracy for English speaking younger adults

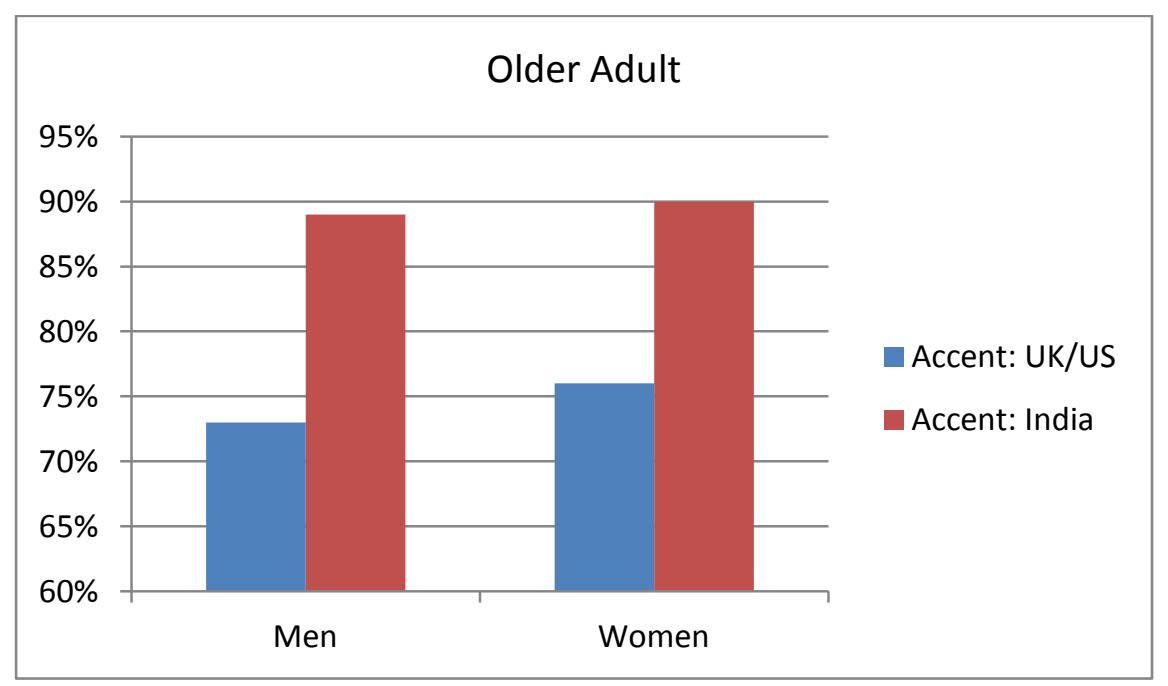

Figure 27: Performance of accuracy for English speaking older adults 


\section{Chapter 5}

\section{CONCLUSION}

Human-robot interaction is an important, attractive and challenging area. There are many way to communicate with robot and speech reorganization is one of them. Speech recognition technology gives us an opportunity to add natural language communication with robot in natural and even way. Robots are building to make people's everyday life easy and so it should be controlled by the human. Human communication media is spoken language; hence speech recognition interference with robot is coined. This simple robot can be very beneficial for many people around the world. This robot can be used in home to collect trash, in lab or people with physical limitations such as handicapped people could use the feature from this thesis to compensate their abilities.

The main target of this project is to build a robot which can communicate with human by speech or voice command and can wander avoiding any blockage. This is a simple prototype of our target. As android device is more popular now a days and it has speech recognition feature we decide on to android device to make an interface with robot. After all the implementation and experiment we have gained lots of experience and found some limitations and problems during this project.

\subsection{Limitations:}

In this project we have managed to reach our target successfully, though it has some limitations. So, we have reached some conclusion about our limitations. First of all we have 
found that our human-robot communication is not properly operative. Real time communication is much more effective to communicate with the robot. But in our case android device's Google speech does not offer that advantage. For every voice command we have to tap the 'press start' button each time which is not faster way to communicate with the robot and it can recognize only one word at a time. Another problem is that Google speech does not work without internet connection before Jelly Bean (version 4.2.2) operation system of android device. In Jelly Bean (version 4.2.2) we have choice to download the offline speech recognition but specific language excluding English (India).

We have used one ultra sonic sensor which slows down the process of detecting the obstacles. Robot has to stop after facing front side obstacles and look around to find out the open space to reposition itself.

\subsection{Future Scope:}

There are lots of scopes to increase the efficiency of this robot. Replacing arduino with Raspberry Pi allows real time communication between robot and human. Using Sphinx or Open CV software in raspberry pi, we can escalate the voice command system. Moreover, we can add camera to transmit video to android device and introduce gesture or face recognition system. Face recognition, gesture and speech recognition will give the robot a multi-modal communication interface. 


\section{References:}

[1] Scopelliti, M., Giuliani, M., and Fornara, 2005, F. Robots in a domestic setting: a psychological approach. Universal Access in the Information Soc., 4(2): 146-155.

[2] K. Wantanabe, Y. Shiraishi, S. Tzafesteas, J. Tang, and T. Fukuda, 1998, Feedback Control of Omnidirectinal Autonomus Platform for Mobile Service Robots, Jornal of Intelligent and Robotic System, 22: 315-330.

[3] M.-J. Jung, H.-S. Kim, S.Kim and J.-H. Kim, 2000, Omni-Directional Mobile Base OK-II Proceeding of the IEEE International Conference on Robotics and Autonomus, 4: 3449-3454.

[4] A Carullo, M Parvis, 2001, An Ultrasonic Sensor for Distance Measurement in Automotive Applications, IEEE Sensors Journal, 1(2): 2-4.

[5] A Willig, K Matheus, A Wolisz, 2005, Wireless Technology in Industrial Networks, Proceedings of the IEEE, 90(6): 1130-1151.

[6] Anderson, S., Liberman, N., Bernstein, E., Foster, S., Cate, E., Levin, B., Hudson, R, 1999. Recognition of elderly speech and voice-driven document retrieval. In Proc. Of IEEE Intl. Conf. on Acoustics, Speech, and Signal Processing, 1:145-148.

[7] B.Siciliano, O. Khatib, 2008. Springer handbook of Robotics, Wursburg: Springer 1:492493. 